\title{
Postoperative conversion disorder in severe anorexia nervosa
}

\author{
Kayo Hirose $\cdot$ Masao Hirose
}

Received: 8 July 2013/Accepted: 12 July 2013/Published online: 27 July 2013

(C) Japanese Society of Anesthesiologists 2013

Keywords Anorexia nervosa - Conversion disorder · Anesthesia

\section{To the Editor:}

We had a case of a 45-year-old woman with history of 25 years of anorexia nervosa, whose body mass index was $15.1 \mathrm{~kg} / \mathrm{m}^{2}$. She underwent posterior cervical spinal fusion to improve spondylolisthesis. Recovery from anesthesia was delayed and sursumversion was observed. In addition, the patient complained of paralysis of the left arm postoperatively. No distinctive positive findings including cerebral hemorrhage or spinal abnormality on the basis of cranial computed tomography and magnetic resonance imaging were found. A few days of observation revealed that she was able to move her hands while sleeping. Finally, we diagnosed her symptoms as postoperative conversion disorder.

Conversion disorder is described as a psychological disorder, characterised by somatic symptoms with no physiological abnormalities, but with an underlying psychological basis [1, 2]. Our patient had the risk factors for conversion disorder, which include a previous physical disability such as anorexia nervosa, and a tendency to occur in adolescent or young adult females under 50 years of age.

Because surgery for severe anorexia nervosa patients is increasing in the 2000s [2], anesthesiologists may encounter postoperative conversion disorder as a stroke mimic or surgical complication.

Conflict of interest There are no conflicts of interest for either author.

\section{References}

1. Segal J, Lam A, Dubrey SW, Vasileiadis E. Stroke mimic: an interesting case of repetitive conversion disorder. BMJ Case Rep. 2012;. doi:10.1136/bcr-2012-007556.

2. Hirose K, Hirose M, Tanaka K, Kawahito S, Tamaki T, Oshita S. Surgical indication and perioperative management of severe anorexia nervosa. Br J Anaesth. 2013 (in press).

K. Hirose $(\bowtie)$

Department of Anesthesiology, National Hospital Organization Kochi National Hospital, 1-2-25 Asakuranishi, Kochi 780-8077, Japan

e-mail: rannrann5656@yahoo.co.jp

M. Hirose

Management Center for Mental and Physical Health, Naruto

University of Education Graduate School, Naruto, Japan 